\title{
Advanced Endometrial Carcinoma
}

National Cancer Institute

\section{Source}

National Cancer Institute. Advanced Endometrial Carcinoma. NCI Thesaurus. Code C159676.

An endometrial carcinoma that has spread extensively to other anatomical sites or is no longer responding to treatment. 